\title{
Acetylation of Nata de coco (bacterial cellulose) and membrane formation
}

\author{
Erika Louise Alberto ${ }^{1}$, Ailey Nicole de Ocampo ${ }^{1}$, Christopere Ghil Depasupi ${ }^{1}$, Mayzonee Ligaray ${ }^{2}$, Ramon Christian \\ Eusebio $^{3}$, Aileen Orbecido ${ }^{1}$, Arnel Beltran ${ }^{1, *}$, and Liza Patacsil ${ }^{2, *}$ \\ ${ }^{1}$ Department of Chemical Engineering, Gokongwei College of Engineering, De La Salle University, 2401 Taft Avenue, Manila 1004, \\ Philippines \\ ${ }^{2}$ Malayan Colleges Laguna, Pulo Diezmo Road, Cabuyao City, Laguna 4025, Philippines \\ ${ }^{3}$ Department of Chemical Engineering, College of Engineering and Agro-Industrial Technology, University of the Philippines Los \\ Baños, College, Laguna 4031, Philippines
}

\begin{abstract}
Nata de coco (NDC), a bacterial cellulose formed by Acetobacter xylinum, was utilized to fabricate a membrane via acetylation and phase inversion methods. The NDC was activated and dissolved in N,N-Dimethylacetamide (DMAc) with lithium chloride ( $\mathrm{LiCl}$ ) at varying amounts of NDC, LiCl/DMAc ratio, activation temperature, and dissolution temperature. Acetylation was done by adding acetic anhydride (in a mass ratio of 1:12 NDC-anhydride) to NDC-DMAc/LiCl solution at a dissolution temperature of 110 ${ }^{\circ} \mathrm{C}$ for 3 hours. The modified-NDC was recovered via precipitation in methanol. The modified-NDC was washed with deionized water then freeze-dried. Modification was verified by determining the degree of substitution (DS) using titration and FTIR analysis. It was observed that the modification could be carried out at an NDC/DMAc (w/v) ratio of $1: 75$ at $120^{\circ} \mathrm{C}$ for 1 hour, and addition of $8 \%(\mathrm{w} / \mathrm{v}) \mathrm{LiCl}$ catalyst at 110 ${ }^{\circ} \mathrm{C}$ for 20 minutes. The DS of the modified-NDC was observed in the range of $2.84-3.69$, which indicates a successful modification. This was further verified by the FTIR results. Membrane fabrication was carried out using the modified-NDC via immersion-precipitation and solvent evaporation methods. A successful membrane formation was observed using solvent evaporation.
\end{abstract}

\section{Introduction}

Nata de coco (NDC), a bacterial cellulose (BC), is a popular gelatinous delicacy in most Southeast Asian countries produced via fermentation of coconut milk assisted by a bacterium belonging to the genus Acetobacter. Although it is generally consumed as food, there has been a significant interest to NDC among the scientific community due to its purity and physiomechanical properties.

Investigation on the potential of $\mathrm{BC}$ as a polymer composite greatly emerged in the recent years. In a study by Lima et al. [1] , acetylation of bacterial cellulose was performed in the $\mathrm{BC}$ dissolve $\mathrm{N}, \mathrm{N}-$ dimethylacetamide/ Lithium chloride $(\mathrm{DMAc} / \mathrm{LiCl})$ ionic solvent system. The degree of substitution (DS) was examined at various cellulose-acetic anhydride ratios of $1: 50,1: 12$, and 1:60. Furthermore, the reaction temperature was also varied. It was determined that the acetylation procedure done with $1: 12$ ratio at $110{ }^{\circ} \mathrm{C}$ would give the highest yield. The result of the degree of substitution for this system was 2.61. However, it was reported that the bacterial cellulose has lost its crystallinity, becoming amorphous.

There are other studies that dealt with the acetylation of dissolved cellulose in $\mathrm{DMAc} / \mathrm{LiCl}$ system using acetic anhydride. Ramos et al. [2] conducted the acetylation at $110{ }^{\circ} \mathrm{C}$ for 4 hours with varying acetic anhydride volume. They reported a DS ranged of 0.28-2.8. At higher acetic anhydride volume, the DS also increased the production of polysubstituted derivatives of cellulose. Ass [3] acetylated sisal and linter cellulose at $110^{\circ} \mathrm{C}$ for 4 hours and 1 hour, respectively. The reported DS was 1.3 for sisal and 1.4-1.5 for linter cellulose. Lastly, El Seoud et al. [4] acetylated plant cellulosic materials at $60{ }^{\circ} \mathrm{C}$ for 18 hours. The acetic anhydride volume was also varied, thus resulting to a wide range of DS acquired. The reported values ranged from 1.5 to 4.5. These studies show that degree of acetylation increases with increasing anhydride concentration and increasing acetylation time.

As far as membrane fabrication is concerned, Dang et al. [5] synthesized forward osmosis (FO) composite membranes from Acetobacter xylinum modified by sodium alginate and cross-linked with calcium chloride. The study showed that the modified BC sheet material was suitable as FO membrane as the salt rejection was relatively high $(98.57 \%)$. However, it has lower water flux (4.80 LMH) compared to 9.283 LMH of the pristine $\mathrm{BC}$ membrane.

In this study, cellulose acetate (CA) from NDC was synthesized through homogeneous acetylation. The

*Corresponding authors: arnel.beltran @ dlsu.edu.ph , 1bpatacsil@ mcl.edu.ph 
effect of activation temperature, NDC/DMAc ratio, $\mathrm{LiCl}$ concertation, and dissolution temperature were observed. The DS was determined using titration, and the presence of acetyl groups in the acetylated NDC was verified via FTIR analysis. The acetylated NDC was then utilized in membrane fabrication via immersion-precipitation method and solvent evaporation method.

\section{Materials and methods}

\subsection{Materials and reagents}

NDC was purchased from Malvar, Batangas (Philippines). DMAc $(\geq 99 \%)$ was purchased from Sigma-Aldrich Co. (USA). LiCl ( $\geq 99 \%$ ) was obtained from LOBA Chemie (India). Nitrogen (high purity) was purchased from Linde Philippines, Inc. (Philippines). Acetic anhydride and dichloromethane (DCM; $\geq 99.9 \%)$ were obtained from Ajax Finechem (Australia). Hydrochloric acid $(\mathrm{HCl} ; 37 \%)$ and methanol ( $\geq 99.9 \%)$ were obtained from RCI Labscan (Thailand). Acetone $(\geq$ $99.5 \%$ ) was obtained from Tedia Company Inc. (USA). Sodium hydroxide pellets $(\mathrm{NaOH}$; AR Grade) and potassium bromide (KBr; AR Grade) were obtained from UNIVAR (USA). Silicon Oil was obtained from QuintStar Petrol Chemical Services (Singapore).

\subsection{Pretreatment of Nata de coco}

The NDC was soaked in $1 \% \mathrm{w} / \mathrm{v} \mathrm{NaOH}$ solution and was washed with distilled water until the $\mathrm{pH}$ of the material became neutral. Afterwards, NDC was shred in a wet blender and was placed in a glass pan for drying in a rapid drying oven at $60{ }^{\circ} \mathrm{C}$ for 6 hours. It was kept in a dry container at room temperature for storage.

\subsection{Dissolution of Nata de coco}

Procedures by El Seoud et al. [4] and Lima et al. [1] were adopted for the dissolution of NDC. A mixture of dried powdered NDC and DMAc with mass to volume ratio ranged from 1:50 to 1:85 was agitated. To activate the dissolution, the mixture was heated to 120,150 , and $170{ }^{\circ} \mathrm{C}$ in an oil bath for 1 hour in a condensing system under nitrogen. Then the mixture was cooled to $110{ }^{\circ} \mathrm{C}$. Five to $8 \%(\mathrm{w} / \mathrm{v}) \mathrm{LiCl}$ was added to the mixture. The temperature at $110{ }^{\circ} \mathrm{C}$ was maintained for 20 minutes. The mixture was continuously stirred at room temperature for 12 hours. Complete dissolution is achieved when there is no powdered NDC that can be visibly detected in the solution and increase in viscosity becomes evident.

\subsection{Acetylation of Nata de coco}

The acetylation of dissolved NDC followed the technique of El Seoud et al. Error! Reference source not found.and Lima et al. [1] and the procedure of Jogunola et al. [6] was employed for the recovery of the acetylated NDC. The dissolved NDC in DMAc/LiCl system was reheated to $110{ }^{\circ} \mathrm{C}$ under nitrogen flow and in a reflux condensing system. Acetic anhydride was then added to the mixture in NDC-to-anhydride proportion of 1:12(w/v). The mixture was stirred at 110 ${ }^{\circ} \mathrm{C}$ for 3 hours. The system was cooled to room temperature. The resulting solution was dispersed in methanol to precipitate the acetylated NDC. The precipitates formed were filtered and were repeatedly washed with deionized water to remove any traces of DMAc, LiCl and other chemicals. Finally, the precipitates were freeze-dried for 2 days and ground into fine powders.

\subsection{Characterization}

The degree of substitution (DS) was determined using titration method [7] One gram of dried acetylated NDC was transferred to a $250 \mathrm{~mL}$ Erlenmeyer flask then $40 \mathrm{~mL}$ of $75 \%$ ethanol was added. The flask was loosely stoppered and was heated to $55^{\circ} \mathrm{C}$ for 1 hour. The same procedure was also done for $1 \mathrm{~g}$ dried NDC (blank). After heating, the flask was tightly stoppered and allowed to stand at room temperature for about 72 hours. The solutions were titrated with $0.5 \mathrm{M} \mathrm{HCl}$ until phenolphthalein end point. Afterwards, $1 \mathrm{~mL}$ of $0.5 \mathrm{M}$ $\mathrm{HCl}$ was added as excess and $\mathrm{NaOH}$ was allowed to diffuse overnight. The disappearance of the faint pink color indicated complete neutralization. The small excess of $\mathrm{HCl}$ was then back titrated with $0.5 \mathrm{M} \mathrm{NaOH}$ solution to phenolphthalein end point. Percent acetyl content (\% Ac) and DS were determined using equations (1) and (2), respectively.

$$
\begin{gathered}
\% A c=\frac{\left[\left(\mathrm{V}_{\mathrm{HCl}, \mathrm{b}}-\mathrm{V}_{\mathrm{HCl}, \mathrm{s}}\right) \mathrm{N}_{\mathrm{HCl}}+\left(\mathrm{V}_{\mathrm{NaOH}, \mathrm{s}}-\mathrm{V}_{\mathrm{NaOH}, \mathrm{b}}\right) \mathrm{N}_{\mathrm{NaOH}}\right]}{\mathrm{m}_{\mathrm{s}}} \times 4.305 \\
\mathrm{DS}=\frac{162 \times \% \mathrm{Ac}}{(4305-43 \times \% \mathrm{Ac})}
\end{gathered}
$$

where, $\mathrm{V}_{\mathrm{NaOH}, \mathrm{s} / \mathrm{b}}$ is the amount of required for titration of the sample and blank, respectively, in $\mathrm{mL} ; \mathrm{N}_{\mathrm{NaOH}}$ is the normality of $\mathrm{NaOH} ; \mathrm{V}_{\mathrm{HCl}, \mathrm{s} / \mathrm{b}}$ is the amount of $\mathrm{HCl}$ required for titration of the sample and blank, respectively, in $\mathrm{mL} ; \mathrm{N}_{\mathrm{HCl}}$ is the normality of $\mathrm{HCl}$; and, $\mathrm{m}_{\mathrm{s}}$ is the weight of the sample in $\mathrm{g}$.

Nicolet 6700 Fourier-transform Infrared (FTIR) spectrometer was utilized to determine the chemical functional groups of the unmodified dried NDC and acetylated NDC. The sample mixed with $\mathrm{KBr}$ was analyzed over a frequency range of 4000 to $500 \mathrm{~cm}^{-1}$.

\subsection{Membrane fabrication via phase inversion method}

\subsubsection{Immersion-precipitation method}

The immersion-precipitation method [8] was employed for the fabrication CA membranes. First, CA in acetone solution in varying dope concent rations of $1 \%$ and $2 \%$ $(\mathrm{w} / \mathrm{v})$ were prepared. The solutions were agitated for 24 hours to ensure complete dissolution. Afterwards, the solutions were degassed for 3 hours in an ultrasonic bath. 
An ample amount of dope solution was poured on a glass plate and was casted using a $30 \mu \mathrm{m}$ casting knife. The film was allowed to evaporate for 20 seconds. Then, the film on the plate was immersed in a water coagulation bath at $20^{\circ} \mathrm{C}$ until the membrane film was formed.

\subsubsection{Solvent evaporation method}

Synthesis of acetylated NDC membrane is in line with the procedure of Villalobos-Rodrigues et al. [9] via solvent evaporation method. Acetylated NDC solutions at $1 \%$ and $2 \%(\mathrm{w} / \mathrm{v})$ in DCM were agitated for 72 hours. The solutions were then degassed for 3 hours in an ultrasonic bath. The resulting solutions were poured in to $150 \mathrm{~mm}$ petri dishes. The petri dishes were then placed in a fume hood with measured temperature of $25^{\circ} \mathrm{C}$ and relative humidity of $60 \%$. The membranes were allowed to form for 90 minutes. Twenty $\mathrm{mL}$ of water were then added to remove the membrane from the dish.

\section{Results and discussion}

\subsection{Dissolution}

\subsubsection{Activation step}

The dissolution of NDC in DMAc was activated by heating NDC in DMAc for 1 hour and shown in Table 1. It was observed that activation at $170{ }^{\circ} \mathrm{C}$ and $150{ }^{\circ} \mathrm{C}$ resulted to discoloration of the mixture. The best condition for activation that exhibited no discoloration was at $120^{\circ} \mathrm{C}$.

Table 1. Qualitative results of the activation procedure.

\begin{tabular}{cccl}
\hline Sample & $\begin{array}{c}\text { NDC/DMAC } \\
(\mathbf{w} / \mathbf{v})\end{array}$ & $\begin{array}{c}\text { Activation } \\
\text { Temperature } \\
(\mathbf{C})\end{array}$ & Observation \\
\hline 1 & $1: 50$ & 170 & Dark Brown \\
2 & $1: 50$ & 150 & Light brown \\
3 & $1: 50$ & 170 & Dark Brown \\
4 & $1: 50$ & 150 & Light Brown \\
5 & $1: 80$ & 150 & Light Brown \\
6 & $1: 80$ & 150 & Light Brown \\
7 & $1: 75$ & 120 & White \\
8 & $1: 75$ & 120 & White \\
9 & $1: 75$ & 120 & White \\
10 & $1: 75$ & 120 & White \\
\hline
\end{tabular}

Activation procedure prior to the actual dissolution step is necessary in order to accelerate the dissolution of NDC that has low solubility due to its high degree of polymerization [10] The activation step increases the diffusion kinetics during dissolution by allowing the polymer chains of NDC to unfold which allow the solvent to easily access the packed crystalline regions of the material. Normally, heat activation of NDC in DMAc is conducted at or near its boiling point [11] Ekmanis [12] explained that at this temperature, the solvent is able to penetrate and swell the cellulose fiber due to its high vapor pressure. However, at high temperatures cellulose undergoes oxidative degradation causing discoloration of the solution. The degradation of NDC occurs when N,Ndimethylacetoacetamide is formed when DMAc condenses [11] This highly reactive intermediate attacks the reducing ends of cellulose via endwise peeling reactions that result to formation of yellow-colored furan derivatives [13]

\subsubsection{Dissolution step}

Table 2 summarizes the effect of $\mathrm{LiCl}$ concentration and temperature in dissolution. The favorable result is a homogenous solution so as to efficiently acetylate NDC.

Table 2. Effect of $\mathrm{LiCl}$ concentration and temperature in the dissolution of NDC.

\begin{tabular}{ccccl}
\hline Sample & $\begin{array}{c}\text { NDC/ } \\
\text { DMAc } \\
(\mathbf{w} / \mathbf{v})\end{array}$ & $\begin{array}{c}\text { Percent } \\
\text { LiCl } \\
(\mathbf{w} / \mathbf{v})\end{array}$ & $\begin{array}{c}\text { Dissolution } \\
\text { Temperature } \\
\left({ }^{\circ} \mathbf{C}\right)\end{array}$ & Observation \\
\hline 1 & $1: 50$ & 5 & 150 & Undissolved \\
2 & $1: 50$ & 5 & 120 & Undissolved \\
3 & $1: 50$ & 8 & 130 & Dissolved \\
4 & $1: 50$ & 8 & 120 & Dissolved \\
5 & $1: 80$ & 0.4 & 110 & Undissolved \\
6 & $1: 80$ & 8 & 110 & Undissolved \\
7 & $1: 75$ & 8 & 110 & Dissolved \\
8 & $1: 75$ & 8 & 110 & Undissolved \\
9 & $1: 75$ & 8 & 110 & Dissolved \\
10 & $1: 75$ & 8 & 110 & Dissolved \\
\hline
\end{tabular}

Samples 1 and 2 resulted to unsuccessful dissolution. The result was due to the size of the dried NDC being dissolved in the mixture. To aid the dissolution process, the material was further ground into fine powder to allow larger surface area in contact with the solvent. Finer material has a greater surface area thereby increasing collision happening between the fluid and the solid which leads to increase in the rate of reaction.

Dissolution was achieved after pulverizing the sample. Furthermore, increasing the $\mathrm{LiCl}$ concentration to $8 \%$ as suggested by Dupont [11] further aided the dissolution of NDC in DMAc. This was supported by the study of Zhang et al. [14] which pointed out that $\mathrm{LiCl}$ causes breakage of the intermolecular hydrogen bonding networks of cellulose via formation of strong hydrogen bonds of hydroxyl protons of cellulose and $\mathrm{Cl}^{-}$anion and through solvation of $\mathrm{Li}^{+}$cation and free DMAc molecules.

Gelatinous solutions were obtained at NDC/DMAc ratio of 1:50. To resolve this problem, the NDC/DMAc ratio was change to $1: 80$ and $1: 75$. The results show that homogenous NDC solution can be attained at an NDC to DMAc ratio of $1: 75$ with $8 \%(\mathrm{w} / \mathrm{v}) \mathrm{LiCl}$ at a dissolution temperature of $110^{\circ} \mathrm{C}$.

A partial dissolution was observed in samples 5 and 6 due to large amount of solution and improper heating. For sample $8, \mathrm{LiCl}$ was first dissolved in a small amount of DMAc before mixing it in the solution. Nonetheless, this method was found ineffective and direct addition of $\mathrm{LiCl}$ in the mixture is recommended. 


\subsection{Acetylation}

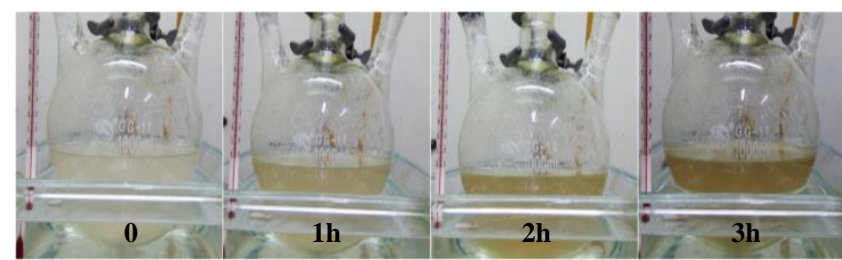

Figure 1. Discoloration of NDC solution through time.

Five successful samples $(3,4,7,9$, and 10) from the dissolution step were acetylated. The acetylation was done in NDC-anhydride ratio of $1: 12$ at $110{ }^{\circ} \mathrm{C}$ for 3 hours. As shown in Fig. 1, it was observed that the discoloration persisted throughout the procedure. The discoloration can be attributed to oxidative degradation of NDC whose rate might have increased via the formation of $\mathrm{N}, \mathrm{N}$-dimethylketeniminium cations in the presence of $\mathrm{LiCl}$ added during the dissolution step. Since the solution was reheated to $110{ }^{\circ} \mathrm{C}$, it is suspected that the furan formation via peeling reaction of NDC with $\mathrm{N}, \mathrm{N}$-dimethylacetoacetamide resumed to occur. N,Ndimethylketeniminium cations, that caused the glyosidic bonds cleavage, allowed more active sites at which the peeling reaction could occur; hence producing more furan derivatives.

\subsubsection{Degree of substitution}

Percent acetyl content was determined by following the titration method. Based from literatures, cellulose acetate has $39.8 \%$ acetyl content while cellulose triacetate ranges from $43-49 \%$. Table 3 shows the percent acetyl content of batches 7, 9, and 10 which indicate that the acetylated NDC were cellulose triacetate form.

Table 3. Calculated percent acetyl groups and degree of substitution of successfully acetylated solutions.

\begin{tabular}{cccc}
\hline Sample & $\begin{array}{c}\text { Acetylation } \\
\text { Temperature } \\
\left({ }^{\circ} \mathbf{C}\right)\end{array}$ & \% Ac & DS \\
\hline 7 & 110 & 49.51 & 3.69 \\
9 & 110 & 45.20 & 3.10 \\
10 & 110 & 43.05 & 2.84 \\
\hline
\end{tabular}

\subsubsection{Chemical functional groups}

The FTIR analysis of NDC and the acetylated NDC is shown in Fig. 2. For the unmodified dried NDC, the peaks at $3420 \mathrm{~cm}^{-1}$ and $1077 \mathrm{~cm}^{-1}$ as shown in Fig. 2(a) represent the hydroxyl group and the - $\mathrm{CO}$ stretching from the hydroxyl group, respectively. These peaks were also particularly present in the FTIR analysis of NDC conducted by Radiman \& Yuliani [15] On the other hand, Fig. 2(b) shows stronger transmittance peaks at $1742 \mathrm{~cm}^{-1}$ and $1069 \mathrm{~cm}^{-1}$ which are attributed to ester carbonyl and $-\mathrm{CO}$ stretching from the acetyl groups, respectively.

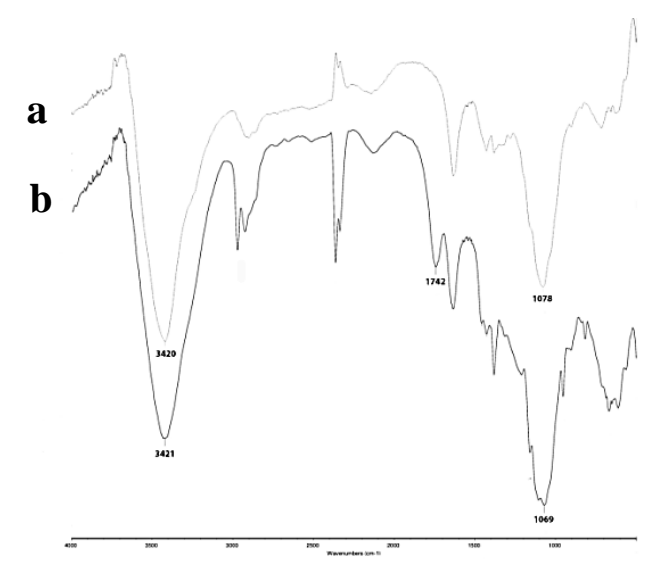

Figure 2. FTIR spectrum of (a) unmodified nata de coco and (b) acetylated of nata de coco.

The FTIR result of the acetylated NDC was akin to the FTIR analysis of cellulose acetate in the studies of Radiman \& Yuliani [15] and Lindu et al. [16] Significantly, the presence of $1742 \mathrm{~cm}^{-1}$ peak in the acetylated NDC and its absence in NDC denotes conversion of hydroxyl groups to acetyl groups and thus, suggests successful acetylation of cellulose. The formation reaction of cellulose to cellulose triacetate is illustrated in Fig. 3.

\subsection{Membrane formation}

Table 4 summarizes the solubility of cellulose acetate and acetylated NDC in acetone and DCM. It can be seen from the data that $\mathrm{CA}$ and acetylated NDC samples were soluble in DCM. While only CA was dissolved in acetone. The solubility of cellulose acetate is dependent on its acetyl content. CA with DS of $2-2.5$ $(\%$ Ac $=39.9 \%)$ are soluble in acetone, dioxane, and DCM while higher degree of substitution types are only soluble in DCM.

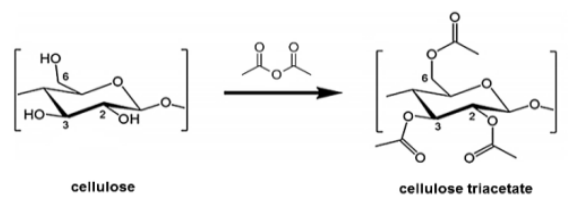

Figure 3. Acetylation reaction of cellulose to cellulose triacetate with acetic anhydride.

Table 1. Solubility data of CA and acetylated NDC in solvents utilized in membrane formation.

\begin{tabular}{lcccc}
\hline \multirow{2}{*}{ Solvent } & \multicolumn{4}{c}{ \% Acetyl Content } \\
\cline { 2 - 5 } & CA & \multicolumn{3}{c}{ Acetylated NDC } \\
\cline { 2 - 5 } & $39.8 \%$ & $43.05 \%$ & $45.20 \%$ & $49.51 \%$ \\
\hline Acetone & Dissolved & Undissolved & Undissolved & Undissolved \\
DCM & Dissolved & Dissolved & Dissolved & Dissolved \\
\hline
\end{tabular}




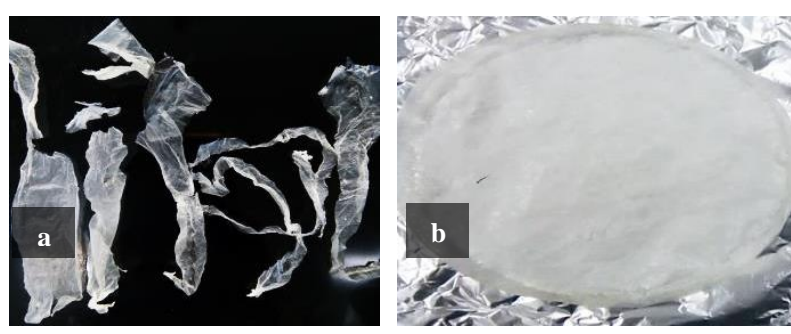

Figure 4. Acetylated NDC membranes formed via (a) immersion-precipitation and (b) solvent evaporation

Although acetylated NDC was found soluble in DCM, it was also noted that the dissolution of acetylated NDC in DCM was at most $2 \% \mathrm{w} / \mathrm{v}$. The acetylated NDC in DCM were both casted through immersion-precipitation and solvent evaporation methods. Fig. 4 presents the membranes formed after performing these methods. The membranes formed via immersion precipitation were not durable and very thin as seen in Fig. 4(a). Whereas, the membranes synthesized via solvent evaporation as shown in Fig. 4(b) was denser, thicker and has a paperlike texture. Due to this, solvent evaporation method was preferred for the formation of acetylated NDC membranes.

\section{Conclusion}

Acetylated cellulose was produced from the acetylation of NDC dissolved in DMAc/LiCl solvent system. NDC, activated at the optimal NDC/DMAc (w/v) ratio of 1:75 at $120{ }^{\circ} \mathrm{C}$ for 1 hour, was dissolved by adding $8 \%(\mathrm{w} / \mathrm{v})$ $\mathrm{LiCl}$ catalyst at $110{ }^{\circ} \mathrm{C}$ for 20 minutes. Acetylation of the dissolved samples by acetic anhydride was performed at NDC/acetic anhydride (w/v) ratio of 1:12 for 3 hours. The degree of substitution of the acetylated NDC ranged from $2.84-3.69$ which means that the acetylated material derived was cellulose triacetate. Membrane fabrication was carried out using the modified-NDC via immersion-precipitation and solvent evaporation methods. A successful membrane formation was observed using solvent evaporation.

This research was financially supported by the Philippine Council for Industry, Energy and Emerging Technology Research and Development of the Department of Science and Technology, Philippines (PCIEERD Project No. 3983).

\section{References}

[1] Lima, G. D., Sierakowski, M., Faria-tischer, P. C. S., \& Tischer, C. A.. Characterization of bacterial cellulose partly acetylated by dimethylacetamide/lithium chloride. Materials Science and Engineering 31(2), 2011, 190-197.

[2] Ramos, L.A., Morgado, D. L., Seoud, O. A. El, da Silva, V., \& Frollini, E. Acetylation of cellulose in LiCl-N,N-dimethylacetamide: first report on the correlation between the reaction efficiency and the aggregation number of dissolved cellulose. Cellulose 18(2), 2011, 385-392.

[3] Ass, B., Ciacco, G. T., \& Frollini, E. Cellulose acetates from linters and sisal: Correlation between synthesis conditions in $\mathrm{DMAc} / \mathrm{LiCl}$ and product properties. Bioresource Technology 97(14), 2006, 1696-1702.

[4] El Seoud, O.A., Marson, G. A., Ciacco, G. T., \& Frollini, E. An efficient, one-pot acylation of cellulose under homogeneous reaction conditions.

[5] Dang, Ngan T.B., Patacsil, L.B., Orbecido, A.H., Eusebio, R.C.P., \& Beltran, A.B. Evaluation of Bacterial Cellulose-Sodium Alginate Forward Osmosis Membrane for Water Recovery. Jurnal Teknologi 80(2-3), 2018, 37-43.

[6] Jogunola, O., Eta, V., Hedenström, M., Sundman, O., Salmi, T., \& Mikkola, J. Ionic liquid mediated technology for synthesis of cellulose acetates using different co-solvents. Carbohydrate Polymers 135, 2016, 341-348.

[7] Fei, P., Liao, L., Cheng, B., \& Song, J. Quantitative analysis of cellulose acetate with a high degree of substitution by FTIR and its application. Analytical Methods 9(43), 2017, 6194-6201.

[8] El-Gendi, A.T. Phase Diagram and Membrane Desalination. Desalination Updates, 2015.

[9] Villalobos-Rodríguez, R., Montero-Cabrera, M., Esparza-Ponce, H., Herrera-Peraza, E., \& Ballinas-Casarrubias, M. Uranium removal from water using cellulose triacetate membranes added with activated carbon. Applied Radiation and Isotopes 70(5), 2012, 872-881.

[10] Shen, X., Ji, Y., Wang, D., \& Yang, Q. Solubility of a High Molecular-Weight Bacterial Cellulose in Lithium Chloride/N,N-dimethylacetamide Solution. Journal of Macromolecular Science, Part B 49(5), 2010, 1012-1018.

[11] Dupont, AL. Cellulose in lithium chloride/N,Ndimethylacetamide, optimisation of a dissolution method using paper substrates and stability of the solutions. Polymer 44(15), 2003, 4117-4126.

[12] Ekmanis JL \& Turbak AF. Lab Highlights 251, Waters Chromatography Division, Millipore, Milford. 1986.

[13] Klemm, Dieter, editor. Polysaccharides II. Springer-Verlag Berlin Heidelberg, 2006.

[14] Zhang, C., Liu, R., Xiang, J., Kang, H., Liu, Z., \& Huang, Y. Dissolution Mechanism of Cellulose in N,N-Dimethylacetamide/Lithium Chloride: Revisiting through Molecular Interactions. The Journal of Physical Chemistry B 118(31), 2014, 9507-9514.

[15] Radiman, C. \& Yuliani, G. Coconut water as a potential resource for cellulose acetate membrane 
preparation. Polymer International 57(3), 2008, 502-508.

[16] Lindu, M., et al. Synthesis and Characterization of Cellulose Acetate from Nata De Coco as Ultrafiltration Membrane. Indonesian Journal of Materials Science 12 (1), 2010, 17-23. 